\title{
Relationship between the Existence of Exercise Partners and Exercise Habits in University Students in Japan
}

\author{
Chiemi Miyawaki ${ }^{*}$, Tomoki Mase ${ }^{2}$, Kumiko Ohara ${ }^{3,4}$, Saori Okuno ${ }^{3}$, Yoshimitsu Okita ${ }^{5}$, \\ Hiratoshi Kaneda', Harunobu Nakamura ${ }^{3}$ \\ ${ }^{1}$ Department of Early Childhood Education, Heian Jogakuin (St. Agnes') College, Kyoto, Japan \\ ${ }^{2}$ Department of Childhood Education, Kyoto Seibo College, Kyoto, Japan \\ ${ }^{3}$ Graduate School of Human Development and Environment, Kobe University, Kobe, Japan \\ ${ }^{4}$ Research Fellow of Japan Society for the Promotion of Science, Tokyo, Japan \\ ${ }^{5}$ Graduate School of Science and Technology, Shizuoka University, Hamamatsu, Japan \\ ${ }^{6}$ Human Sciences Research Center, Osaka Electro-Communication University, Shijonawate, Japan \\ Email: ${ }^{*}$ c-miyawaki@heian.ac.jp
}

Received 5 July 2014; revised 22 August 2014; accepted 5 September 2014

Copyright (C) 2014 by authors and Scientific Research Publishing Inc.

This work is licensed under the Creative Commons Attribution International License (CC BY).

http://creativecommons.org/licenses/by/4.0/

cC) (7) Open Access

\begin{abstract}
We investigated the relationships between the existence of exercise partners and exercise habits among Japanese university students. Subjects were 650 university students (539 males, 111 females; age range 18 - 27 years). They responded to an anonymous questionnaire asking about current and past exercise habits, preference for exercise (i.e., like or dislike of exercise), and the existence of one or more exercise partners. In the results, the existence of exercise partners had a significant association with exercise habits at each school stage in both genders. Exercise preference had a significant association with exercise habits during high school in both genders; during primary and middle school, however, this association was significant only in males. In males, exercise habits and the preference for exercising in high school affected current exercise habits. In females, only exercise habits in high school affected current exercise habits. Our results suggest that the existence of one or more exercise partners is important for the practice of exercise, as well as the preference for exercise. They also suggest that continuity of exercise habits is different between males and females.
\end{abstract}

\section{Keywords}

Exercise Habits, Exercise Partners, Japanese Students, Preference for Exercising

\footnotetext{
${ }^{*}$ Corresponding author.
}

How to cite this paper: Miyawaki, C., Mase, T., Ohara, K., Okuno, S., Okita, Y., Kaneda, H. and Nakamura, H. (2014) Relationship between the Existence of Exercise Partners and Exercise Habits in University Students in Japan. Health, 6, 21292134. http://dx.doi.org/10.4236/health.2014.616247 


\section{Introduction}

Previous studies have reported that moderate exercise is effective for the prevention of age-related diseases such as cancer and cardiovascular diseases [1]-[6]. The exercise guidelines updated by the U.S. Department of Health and Human Services in 2008 recommend at least 150 minutes a week of moderate-intensity aerobic physical activity, 75 minutes a week of vigorous-intensity aerobic physical activity, or an equivalent combination of the two [7]. Nevertheless, about 35\% of individuals in the U.S. do not meet these recommendations [8]. In Japan, research has also found a lack of physical activity. A 2010 report showed that only about 34.8\% of men and $28.5 \%$ of women engaged in exercise for a minimum of $30 \mathrm{~min}$ at least twice a week [9].

Regarding the factors related to establishing exercise habits, Salmon et al. [10] and Hirose [11] reported that survey respondents who reported high levels of enjoyment and preference for physical activity were more likely to report high levels of activity. The presence of a partner to exercise with has also been identified as an important factor in exercise [12]-[14]. In contrast, the lack of social support from family or friends is associated with lower levels of exercise [15] [16]. Trost et al. [17], Bauer et al. [18], and Dowda et al. [19] showed that support from family or friends had a significant positive influence on exercise in adolescents. However, the extent to which these factors are relevant to the establishment of exercise habits has, to the best of our knowledge, not been fully determined.

In this study, we investigated the association of current and past preference for exercise and existence of exercise partners in Japanese university students.

\section{Methods}

\subsection{Subjects}

Subjects were 765 university students. A survey was conducted using an anonymous self-administered questionnaire distributed in university classes during December 2010. The valid response rate was 85.0\% ( $\mathrm{n}=650$; 539 males, 111 females). Respondents’ ages ranged from 18 - 27 years. We categorized the subjects into two groups: an "exercise group" who reported engaging in some form of physical exercise two or more times per week, and a "non-exercise group" who reported exercising less than twice a week. All participants gave informed consent to participate, and the study was approved by Human Ethics Committee of Graduate School of Human Development and Environment, Kobe University.

\subsection{Questionnaire}

The questionnaire asked about respondents’ age, gender, current and past exercise habits, current and past preference for exercise, and "whether the respondent has a partner such as a family member or friend to exercise together with" (current and past existence of partner). With regard to past exercise habits, the questionnaire solicited information regarding respondents' exercise habits, preference for exercise, and existence of an exercise partner during their school years (i.e., elementary, junior high school, and high school).

Current exercise habits were assessed as frequency per week of activity of 30 min or more; response options ranged from 0 - 7 times/week. To determine respondents' exercise habits in elementary school, junior high school, and high school, the questionnaire included items such as, "Did you exercise except physical education class when you were in elementary/junior high/high school?”; response options were simply "yes” or "no”. Current and past preference for exercise was surveyed with the following response options: "like exercise", "slightly like exercise”, "slightly dislike exercise”, and "dislike exercise”. Response options regarding current and past exercise partner (s) were "many”, "some”, "few”, and “none”.

\subsection{Analysis}

For the purposes of the analysis, the items regarding preference for exercise were collapsed. The responses "like to exercise" and "slightly like to exercise" were collapsed into "like to exercise"; similarly, "slightly dislike to exercise" and "dislike to exercise” were collapsed into "dislike to exercise”. For questionnaire items regarding the existence of partner(s), the responses "many" and "some” were collapsed into "exist", while "few" and "none” were collapsed into "do not exist".

A binomial logistic regression analysis was conducted to evaluate the relationships among current exercise habits and "[current] and [past] preference for exercise”, and "[current] and [past] existence of partner(s)". Dif- 
ferences with values of $\mathrm{p}<0.05$ were considered significant. The statistical analyses were performed using SPSS $^{\circledR} 19.0 \mathrm{~J}$ for Windows.

\section{Results}

The associations between exercise habits, preference for exercising, and the exercise partners are presented in Tables 1-3. During primary school, males who had a preference for exercise were significantly more likely to have had an exercise habit $(\mathrm{OR}=2.51, \mathrm{p}=0.002)$. Males with exercise partners were also significantly more likely to have had an exercise habit $(\mathrm{OR}=4.15, \mathrm{p}<0.001)$. In females also, those who had exercise partners were significantly more likely to have had an exercise habit $(\mathrm{OR}=4.11, \mathrm{p}=0.011)$ (Table 1$)$.

Again during middle school, males who had a preference for exercise were significantly more likely to have had an exercise habit $(\mathrm{OR}=3.37, \mathrm{p}<0.001)$, as were males with exercise partners $(\mathrm{OR}=6.59, \mathrm{p}<0.001)$. In females, those with an exercise partners were significantly more likely to have had an exercise habit $(\mathrm{OR}=$ 32.92, $\mathrm{p}<0.011$ ) (Table 2).

In high school, males who had a preference for exercise were significantly more likely to have had an exercise habit $(\mathrm{OR}=3.34, \mathrm{p}<0.001)$, as were those with exercise partners $(\mathrm{OR}=6.59, \mathrm{p}<0.001)$. The same was true for females. Those who had a preference for exercise were significantly more likely to have had an exercise habit $(\mathrm{OR}=4.14, \mathrm{p}=0.034)$, as were those with exercise partners $(\mathrm{OR}=13.41, \mathrm{p}<0.001)$ (Table 3).

Associations between current exercise habits and past exercise habits, preference, and exercise partners are listed in Table 4 and Table 5.

In males, those who exercised habitually during high school were significantly more likely to have had an exercise habit $(\mathrm{OR}=3.34, \mathrm{p}<0.001)$. Likewise, those who had a preference for exercise in high school were significantly more likely to have had an exercise habit $(\mathrm{OR}=3.34, \mathrm{p}<0.001)$, as were those who had exercise partners $(\mathrm{OR}=3.34, \mathrm{p}<0.001)$ (Table 4).

Table 1. Associations of exercise habits with the preference for exercising and the exercise partners in primary school.

\begin{tabular}{cccc}
\hline & OR & $95 \%$ CI & p-value \\
\hline Males & & & \\
Preference for exercise & 2.51 & $(1.41-4.46)$ & $<002$ \\
Exercise partners & 4.15 & $(2.42-7.11)$ & 0.001 \\
Females & & & 0.089 \\
Preference for exercise & 2.65 & $(0.86-8.14)$ & 0.011 \\
Exercise partners & 4.11 & $(1.39-12.18)$ & \\
\hline
\end{tabular}

The dependent variable was exercise habits in primary school. The independent variables were "preference for exercising” and "exercise partners" in primary school. OR: odds ratio; CI: confidential interval.

Table 2. Associations of exercise habits with the preference for exercising and the exercise partners in middle school.

\begin{tabular}{cccc}
\hline & OR & $95 \%$ CI & p-value \\
\hline Males & & & $<0.001$ \\
Preference for exercise & 3.37 & $(1.80-6.32)$ & $<0.001$ \\
Exercise partners & 6.59 & $(3.56-12.18)$ & 0.998 \\
Females & & $(0.24-4.21)$ & $<0.001$ \\
Preference for exercise & 1.00 & $(8.35-129.82)$ & \\
Exercise partners & 32.92 & & \\
\hline
\end{tabular}

The dependent variable was exercise habits in middle school. The independent variables were "preference for exercising” and "exercise partners” in middle school. OR: odds ratio; CI: confidential interval. 
Table 3. Associations of exercise habits with the preference for exercising and the exercise partners in high school.

\begin{tabular}{cccc}
\hline & OR & $95 \%$ CI & p-value \\
\hline Males & & & $<0.001$ \\
Preference for exercise & 3.34 & $(1.94-5.74)$ & $<0.001$ \\
Exercise partners & 6.59 & $(4.20-10.34)$ & \\
Females & & & 0.034 \\
Preference for exercise & 4.14 & $(1.12-15.35)$ & $<0.001$ \\
Exercise partners & 13.41 & $(4.77-37.73)$ & \\
\hline
\end{tabular}

The dependent variable was exercise habits in high school. The independent variables were "preference for exercising" and "exercise partners" in high school. OR: odds ratio; CI: confidential interval.

Table 4. Associations between current exercise habits and past exercise habits, preference, and exercise partners in males.

\begin{tabular}{cccc}
\hline & OR & $95 \%$ CI & p-value \\
\hline Males & & & \\
Exercise habits in primary school & 1.13 & $(0.70-1.81)$ & 0.627 \\
Exercise habits in middle school & 1.42 & $(0.76-2.62)$ & 0.270 \\
Exercise habits in high school & 2.17 & $(1.43-3.29)$ & $<0.001$ \\
Preference for exercising in primary school & 1.32 & $(0.70-2.50)$ & 0.386 \\
Preference for exercising in middle school & 1.28 & $(0.78-2.42)$ & 0.435 \\
Preference for exercising in high school & 2.64 & $(1.50-4.70)$ & 0.001 \\
Exercise partners in primary school & 1.28 & $(0.62-2.62)$ & 0.495 \\
Exercise partners in middle school & 1.53 & $(0.70-3.40)$ & 0.288 \\
Exercise partners in high school & 2.20 & $(1.32-3.64)$ & 0.003 \\
\hline
\end{tabular}

The dependent variable was "current exercise habits.” The independent variables were "past exercise habits”, "preference for exercising”, and "exercise partners”. OR: odds ratio; CI: confidential interval.

Table 5. Associations of current exercise habits with past exercise habits, preference, and exercise partners in in females.

\begin{tabular}{cccc}
\hline & OR & $95 \%$ CI & p-value \\
\hline Females & & & \\
Exercise habits in primary school & 1.28 & $(0.53-3.09)$ & 0.586 \\
Exercise habits in middle school & 0.85 & $(0.32-2.28)$ & 0.752 \\
Exercise habits in high school & 4.32 & $(1.72-10.86)$ & 0.002 \\
Preference for exercising in primary school & 1.20 & $(0.39-3.70)$ & 0.756 \\
Preference for exercising in middle school & 0.77 & $(0.25-2.40)$ & 0.646 \\
Preference for exercising in high school & 2.97 & $(0.90-9.83)$ & 0.074 \\
Exercise partners in primary school & 0.94 & $(0.30-2.91)$ & 0.909 \\
Exercise partners in middle school & 1.35 & $(0.39-4.69)$ & 0.635 \\
Exercise partners in high school & 2.31 & $(0.85-6.27)$ & 0.100
\end{tabular}

The dependent variable was "current exercise habits". The independent variables were "past exercise habits", "preference for exercising”, and "exercise partners". OR: odds ratio; CI: confidential interval. 
In females, those who exercised habitually during high school were also significantly more likely to have had an exercise habit $(\mathrm{OR}=3.34, \mathrm{p}<0.001)$. Additionally, those who had a preference for exercise in high school were significantly more likely to have had an exercise habit (OR $=3.34, \mathrm{p}<0.001$ ), as were those who had exercise partners $(\mathrm{OR}=3.34, \mathrm{p}<0.001)$ (Table 5).

\section{Discussion}

The main findings of this study were: (1) in both genders, the existence of exercise partners had a significant association with exercise habits at each school stage. On the other hand, while preference for exercise had a significant association with exercise habits in both genders in high school, this association was significant in primary and middle school only in males; (2) in males, exercise habits and a preference for exercise in high school affected current exercise habits, but they did not do so in earlier school stages. In females, only exercise habits in high school affected current exercise habits.

In the present study, exercise partners were positively associated with exercise habits at each school stage in both genders. In addition, exercise partners had strong association with exercise habits comparing with preference for exercise. These results indicate that the existence of exercise partners, as well as a preference for exercise, plays an important role in establishing an exercise habit. Previous studies also reported that support from family or friends had a significant positive influence on exercise in adolescents [12]-[14], which supports the present results.

We also observed that exercise habits in high school affected current exercise habits in both genders. This indicates a possibility that when exercise habits are more recent, they are also more likely to continue. Similar results were shown in preference for exercise and exercise partners in males, but not in females. However, this does not necessarily refute the importance of exercise partner in females. Previous studies reported gender differences in motivation for exercise [20]-[22], with males demonstrating more internal motivations for exercise than females. This difference in internal motivation may have affected the continuity of exercise habits in the present study.

Some limitations of this study should be noted. First, its cross-sectional design precluded drawing conclusions about any kind of cause-effect relationship. Second, the samples were collected from a limited area in Japan. In addition, a minimum sample size was not calculated before sampling. However, the number of samples was 650 in the present study, which is considered enough for analysis.

\section{Conclusion}

Exercise partners and a preference for exercising were found to be important in maintaining exercise habits into young adulthood in a sample of Japanese university students. We also found that continuity of exercise habits was different between males and females. From these results, the immediate need for the practice of exercise is looking for a partner regardless of past exercise history.

\section{Acknowledgements}

We thank the university students who participated in this study. We acknowledge the work of all the teachers who conducted data collection.

\section{References}

[1] U.S. Department of Health and Human Services (1996) Physical Activity and Health: A Report of the Surgeon General. Atlanta, GA: U.S. Dept of Health and Human Services, Centers for Disease Control and Prevention, National Center for Chronic Disease Prevention and Health Promotion. http://www.cdc.gov/nccdphp/sgr/pdf/sgrfull.pdf

[2] Anzuini, F., Battistella, A. and Izzotti, A. (2011) Physical Activity and Cancer Prevention: A Review of Current Evidence and Biological Mechanisms. Journal of Preventive Medicine and Hygiene, 52, 174-180.

[3] Church, T. (2011) Exercise in Obesity, Metabolic Syndrome, and Diabetes. Progress in Cardiovascular Diseases, 53, 412-418. http://dx.doi.org/10.1016/j.pcad.2011.03.013

[4] Li, J. and Siegrist, J. (2012) Physical Activity and Risk of Cardiovascular Disease-A Meta-Analysis of Prospective Cohort Studies. International Journal of Environmental Research and Public Health, 9, 391-407. http://dx.doi.org/10.3390/ijerph9020391 
[5] Blair, S.N., Cheng, Y. and Holder, J.S. (2001) Is Physical Activity or Physical Fitness More Important in Defining Health Benefits? Medicine and Science in Sports and Exercise, 33, S379-S399; discussion S419-S420.

[6] Pham, N.M., Mizoue, T., Tanaka, K., Tsuji, I., Tamakoshi, A., Matsuo, K., Ito, H., Wakai, K., Nagata, C., Sasazuki, S., Inoue, M. and Tsugane, T. for the Research Group for the Development and Evaluation of Cancer Prevention Strategies in Japan (2012) Physical Activity and Colorectal Cancer Risk: An Evaluation Based on a Systematic Review of Epidemiologic Evidence among the Japanese Population. Japanese Journal of Clinical Oncology, 42, 2-13.

http://dx.doi.org/10.1093/jjco/hyr160

[7] U.S. Department of Health and Human Services (2008) 2008 Physical Activity Guidelines for Americans. US Department of Health and Human Services. http://www.health.gov/paguidelines/pdf/paguide.pdf

[8] U.S. Department of Health and Human Services (2010) State Indicator Report on Physical Activity, 2010. US Department of Health and Human Services. http://www.cdc.gov/physicalactivity/downloads/PA_State_Indicator_Report_2010.pdf

[9] Ministry of Health Labor and Welfare of Japan (2012) The National Health and Nutrition Survey 2012. http://www.mhlw.go.jp/stf/houdou/2r98520000020qbb-att/2r98520000021c1g.pdf

[10] Salmon, J., Owen, N., Crawford, D., Bauman, A. and Sallis, J.F. (2003) Physical Activity and Sedentary Behavior: A Population-Based Study of Barriers, Enjoyment, and Preference. Health Psychology, 22, 178-188.

[11] Hirose, N. and Maruyama, H. (2010) Effect of "Like" or "Dislike” of Exercise on Amount of Physical Activity and Duration of Activities of Daily Living. Rigakuryohokagaku, 25, 699-703.

[12] Steptoe, A., Wardle, J., Fuller, R., Holte, A., Justo, J., Sanderman, R. and Wichstrom, L. (1997) Leisure-Time Physical Exercise: Prevalence, Attitudinal Correlates, and Behavioral Correlates among Young Europeans from 21 Countries. Preventive Medicine, 26, 845-854. http://dx.doi.org/10.1006/pmed.1997.0224

[13] Sternfeld, B., Ainsworth, B.E. and Quesenberry, C.P. (1999) Physical Activity Patterns in a Diverse Population of Women. Preventive Medicine, 28, 313-323. http://dx.doi.org/10.1006/pmed.1998.0470

[14] Treiber, F.A., Baranowski, T., Braden, D.S., Strong, W.B., Levy, M. and Knox, W. (1991) Social Support for Exercise: Relationship to Physical Activity in Young Adults. Preventive Medicine, 20, 737-750. http://dx.doi.org/10.1016/0091-7435(91)90068-F

[15] Leslie, E., Owen, N., Salmon, J., Bauman, A., Sallis, J.F. and Lo, S.K. (1999) Insufficiently Active Australian College Students: Perceived Personal, Social, and Environmental Influences. Preventive Medicine, 28, 20-27. http://dx.doi.org/10.1006/pmed.1998.0375

[16] Sallis, J.F., Hovell, M.F. and Hofstetter, C.R. (1992) Predictors of Adoption and Maintenance of Vigorous Physical Activity in Men and Women. Preventive Medicine, 21, 237-251. http://dx.doi.org/10.1016/0091-7435(92)90022-A

[17] Trost, S.G., Sallis, J.F., Pate, R.R., Freedson, P.S., Taylor, W.C. and Dowda, M. (2003) Evaluating a Model of Parental Influence on Youth Physical Activity. American Journal of Preventive Medicine, 25, 277-282. http://dx.doi.org/10.1016/S0749-3797(03)00217-4

[18] Bauer, K.W., Nelson, M.C., Boutelle, K.N. and Neumark-Sztainer, D. (2008) Parental Influences on Adolescents' Physical Activity and Sedentary Behavior: Longitudinal Findings from Project EAT-II. International Journal of Behavioral Nutrition and Physical Activity, 5, 12. http://dx.doi.org/10.1186/1479-5868-5-12

[19] Dowda, M., Dishman, R.K., Pfeiffer, K.A. and Pate, R.R. (2007) Family Support for Physical Activity in Girls from 8th to 12th Grade in South Carolina. Preventive Medicine, 44, 153-159. http://dx.doi.org/10.1016/j.ypmed.2006.10.001

[20] Patterson, E., McGeough, D., Cannon, E., et al. (2006) Self-Efficacy, Stages of Change and Physical Activity in Irish College Students. Journal of Public Health, 14, 81-86. http://dx.doi.org/10.1007/s10389-006-0028-6

[21] Allison, K.R., Dwyer, J.J.M. and Makin, S. (1999) Perceived Barriers to Physical Activity among High School Students. Preventive Medicine, 28, 608-615. http://dx.doi.org/10.1006/pmed.1999.0489

[22] Pauline, J.S. (2013) Physical Activity Behaviors, Motivation, and Self-Efficacy among College Students. College Student Journal, 47, 64-74. 
Scientific Research Publishing (SCIRP) is one of the largest Open Access journal publishers. It is currently publishing more than 200 open access, online, peer-reviewed journals covering a wide range of academic disciplines. SCIRP serves the worldwide academic communities and contributes to the progress and application of science with its publication.

Other selected journals from SCIRP are listed as below. Submit your manuscript to us via either submit@scirp.org or Online Submission Portal.
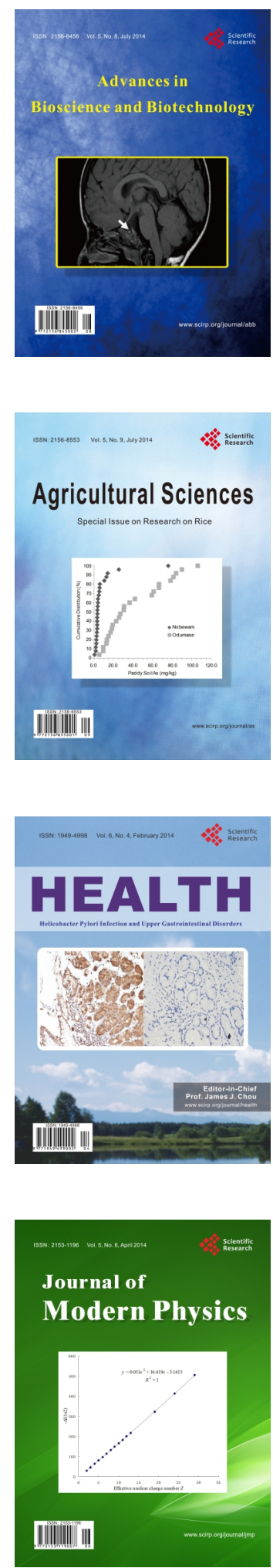
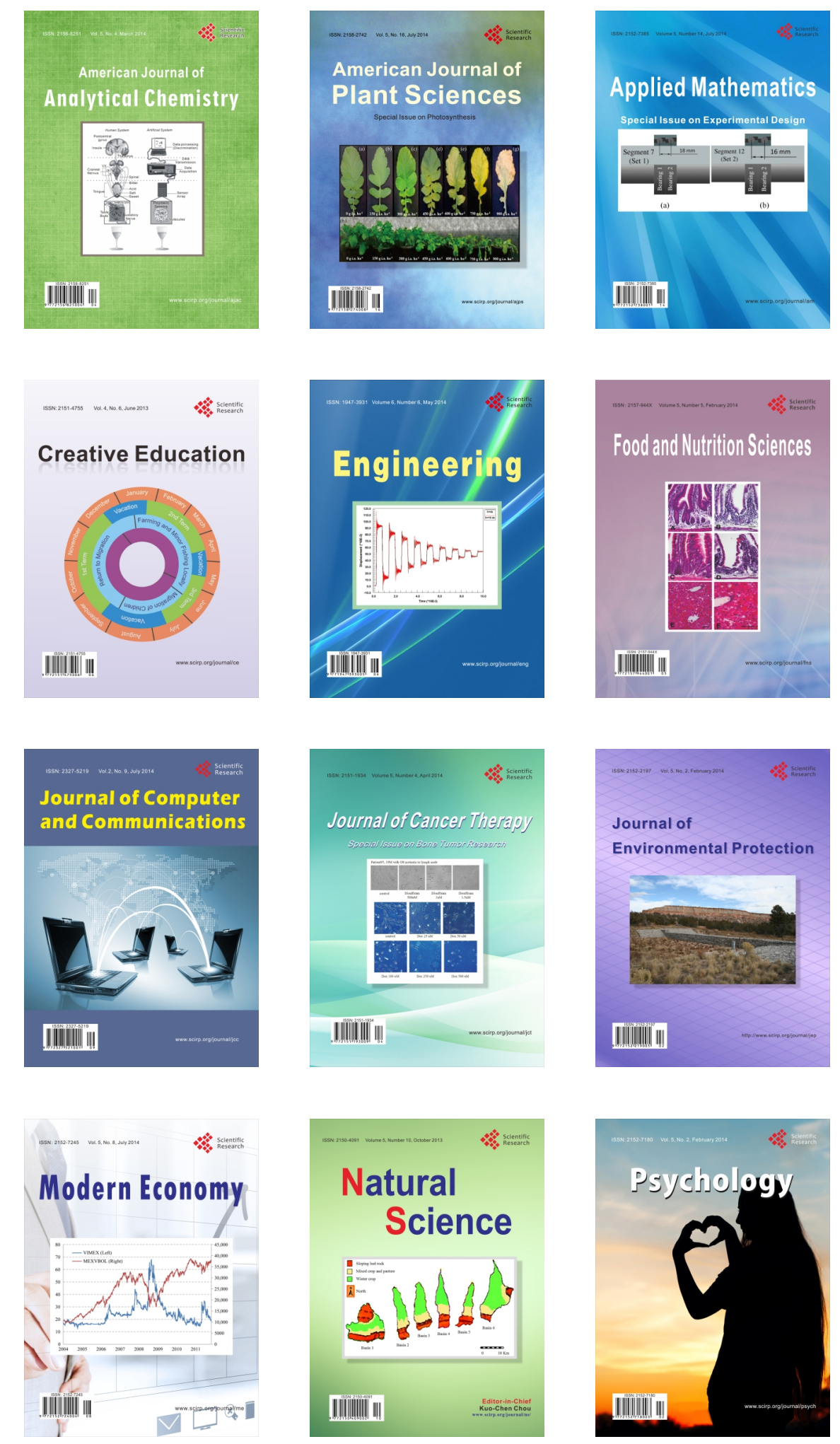